\title{
A review of randomized clinical trials on the effect of aromatherapy with lavender on labor pain relief
}

\begin{abstract}
Background: Labor is a painful process and labor pain management is one of the essential aspects of obstetrical services and the main goal of intrapartum care. Aromatherapy is one of the traditional medicine methods for labor pain relief. This systematic review and meta-analysis aimed to critically evaluate and summarize all the available evidence from randomized clinical trials (RCTs) on the effect of aromatherapy with lavender on labor pain relief.

Methods: Scientific search was performed in MEDLINE/PubMed, Cochrane library, Cochrane Central Register of Controlled Trials (CENTRAL) and Scopus from their inception until September 2015 using the strategy (Lavender* OR Lavandula* OR silexan) AND (labor OR labour OR birth OR childbirth). In addition, we searched Google Scholar with the aim of exploring the citations of final studies included in the systematic review. Data extraction was done by two authors independently. Cochrane tool was used to evaluate the quality of citations. Comprehensive Meta-Analysis Version 2 was used for statistical analysis.
\end{abstract}

Results: based on the search strategy, 192 primary papers were found. Finally, 3 RCTs were included in the systematic review. Overall, the quality of the studies included in the review was moderate and mixed. The results showed that Lavender aromatherapy via inhalation decreased the labor pain by the order of $-0.476[-0.718--0.235], \mathrm{p}=0.000$ $\left(\mathrm{I}^{2}=0 \%, \mathrm{p}=0.7\right)$. Also, massage aromatherapy by lavender oil decreased the labor pain significantly $(-0.907[-1.438--0.375], \mathrm{p}=0.001)$

Conclusion: Although the results of this review showed the labor pain relief with lavender aromatherapy, but more rigorous RCTs with higher quality is required to achieve a precise result.

Keywords: aromatherapy, lavender, childbirth, pain management, statistical analysis
Volume I Issue 3 - 2016

\author{
Somayeh Makvandi,' Masoumeh \\ Mirteimoori, ${ }^{2}$ Khadijeh Mirzaei Najmabadi,' \\ Ramin Sadeghi ${ }^{3}$ \\ 'Department of Midwifery, School of Nursing and Midwifery, \\ Mashhad University of Medical Sciences, Iran \\ ${ }^{2}$ Department of Obstetrics and Gynecology, School of Medicine, \\ Mashhad University of Medical Sciences, Iran \\ ${ }^{3}$ Department of Nuclear Medicine, Nuclear Medicine Research \\ Center, Mashhad University of Medical Sciences, Iran
}

\section{Correspondence: Masoumeh Mirteimoori, Department of Obstetrics and Gynecology, School of Medicine, Mashhad University of Medical Sciences, Iran, Tel 009891531068 75, Email mirteimourim@mums.ac.ir}

Received: November 15, 2016 | Published: December 0I, 2016

\section{Introduction}

Childbirth is one of the most painful phenomena that women will tolerate in their lifetime. Labor pain is recognized as one of the most severe human pain. ${ }^{1,2}$ Severe pain associated to vaginal delivery can cause abnormal uterine action during labor which might lead to increased medical interventions such as caesarian section $(\mathrm{C} / \mathrm{S})$. ${ }^{3}$ According to world health report, the rate of $\mathrm{C} / \mathrm{S}$ in Iran is too high ${ }^{4}$ and up to $60 \%$ of Iranian women are interested in $\mathrm{C} / \mathrm{S}$ to endure less pain during childbirth. ${ }^{5}$ Meanwhile, it has been reported that the risk of maternal death after a $\mathrm{C} / \mathrm{S}$ is five times more than normal vaginal delivery, ${ }^{6}$ yet suffering severe labor pain during vaginal delivery may affect women's decision on the mode of delivery in their future pregnancies.

Management and control of labor pain is an important aspect of intra partum care. ${ }^{7}$ Some pharmaceutical and non-pharmaceutical methods have been used for this purpose. ${ }^{8}$ There are some evidence to support the efficacy of selected pharmaceutical labor pain relief agents, but an overview of systematic reviews also highlighted the association of some pharmaceutical labor pain relief methods with a number of side effects. ${ }^{9}$ Also In the pharmaceutical methods, the pain feeling would be reduced physiologically, but psychological and emotional conditions of the childbearing mothers are ignored.

Non-pharmaceutical methods of labor pain relief are frequently simple to use, applicable and cheap, and can be used as a supplementary treatment with other pharmaceutical agents. ${ }^{10}$ In contrast, although most non-pharmaceutical pain management options are non-invasive and safe for mother and fetus, their efficacy remains unclear due to a lack of high quality evidence. ${ }^{9,10}$ These methods are including heat and cold therapy, touch therapy, massage, reflexology, relaxation, dancing, chewing sugar free gum, trans or subcutaneous nerve stimulation, water therapy, using a birth ball, music therapy, acupressure and aromatherapy. ${ }^{11-13}$

One of the non-pharmaceutical a method of labor pain relief is using of aromatherapy. Specifically, aromatherapy involves the use of essential oils to restore balance and improve well-being. ${ }^{14,15}$ Several studies showed the effectiveness of aromatherapy for pain and anxiety relief of hospitalized patients, ${ }^{16}$ for relief of postoperative nausea and vomiting, ${ }^{17}$ on hemodynamic indices among patients with acute coronary syndrome ${ }^{18}$ and improvement of life quality in women with breast cancer. ${ }^{19}$ Also aromatherapy has many applications in women's health, including reduction of labor pain, episiotomy wound healing, ${ }^{20}$ treatment of post $\mathrm{C} / \mathrm{S}$ nausea, ${ }^{21}$ improvement of primary dysmenorrheal, ${ }^{22}$ treatment of depression in postmenopausal women. ${ }^{23}$ Tillett' study (2010) showed that the use of essential oils has not been shown to cause complications and it has an overall acceptability among women. ${ }^{24}$

In general, various aromatherapy essences, including lavender, eucalyptus, salvia, jasmine, and rose, are used in labor. ${ }^{25,26}$ These essential oils are used in different ways including topical application, inhalation, baths, and compresses. ${ }^{27}$ 
Lavender (Lavandula angustifolia), which belongs to green mint family and aromatic plants is one of the most used aromatic plants in aromatherapy. ${ }^{28}$ It consists of linalool, alcohol, ketones, esters, and aldehydes. The ketones in lavender effectively decrease pain and inflammation, and contribute to falling asleep. Esters prevent muscle spasms, and reduce tension and depression..$^{29} \mathrm{Jarada}^{30}$ study showed that Lavender was a folk medicinal plant with some Traditional uses such as treatment of cough, eczema, rheumatism, migraine and was used as a diuretic, carminative, and antispasmodic sedative. ${ }^{30}$

Some studies suggest using Lavender aromatherapy for pain and anxiety management during labor. However, the effectiveness of non-pharmacologic approaches such as Lavender aromatherapy on obstetric interventions and outcomes has remained unclear, and there is still no consensus for the use of Lavender aromatherapy for pain relief in hospital settings. The difficulty to translate this approach into practice may be explained by the lack of a systematic review assessing the impact of using Lavender aromatherapy on labor pain relief

Therefore, this systematic review and meta-analysis was undertaken to critically summarize all the evidence from randomized clinical trials (RCTs) of Lavender aromatherapy as a supportive analgesic method during labor. The availability of such information would be useful for all stakeholders such as women, medicine and midwifery students, midwives, nurses, gynecologists and health policymakers.

\section{Methods}

\section{Data sources and search strategy}

Two of authors conducted search in the MEDLINE/PubMed, Cochrane library, Cochrane Central Register of Controlled Trials (CENTRAL) and Scopus from their inception to September 2015. In addition, we searched data base of Google Scholar_with the aim of exploring the citations of final studies included in the systematic review.

The search strategy used was: (Lavender* OR Lavandula* OR silexan) AND (labor OR labour OR Obstetric OR birth OR childbirth). We imposed no language restrictions. The reference lists of papers were checked for further relevant citations. Personal contact was made with the authors of the studies, if necessary, to request for additional data.

\section{Inclusion criteria}

We planned to include RCTs for inclusion in this review. We considered studies for inclusion in this systematic review in which Lavender aromatherapy was explicated in any form during any stage of labor to relieve the labor pain. Gray literature was not included.

\section{Outcome measure}

Our outcome measure was pain relief during labor. This is usually measured with a $10 \mathrm{~cm}$ visual analogue scale (VAS) which is a sensitive and efficient method for measuring pain. We used difference in means of pre/post intervention VAS changes in the treatment group as compared to the placebo, as the main effect size measure.

\section{Study selection}

Two authors independently reviewed the titles and abstracts of the records identified through database searching and excluded irrelevant studies. Then they independently retrieved the full paper of seemingly relevant studies and examined them to select the final set of included studies based on the inclusion criteria. Any type of disagreement between authors was resolved by discussion.

\section{Data extraction}

The reviewers designed a data extraction form. Data were extracted by two reviewers using the agreed form, independently. This included: first author's name, year of publication, country, participants, intervention and comparison, as well as outcome. Disagreements were resolved by discussion and consensus.

\section{Risk of bias assessment}

All Studies included in the systematic review were assessed by two reviewers independently for their risk of bias using the Cochrane risk of bias tool. ${ }^{31}$ This tool consists of some domains including sequence generation; allocation concealment; blinding of participants and personnel, blinding of outcomes assessors; incomplete outcome data; selective outcome reporting; and other source of bias. Each domain was rated as low, unclear, or high risk. Disagreements were resolved by discussion and consensus.

\section{Statistical analysis}

We used random effects model in order to pool effect sizes across the included studies. For heterogeneity evaluation, Cochrane $Q$ value $(\mathrm{p}<0.05$ was considered statistically significant) and $\mathrm{I} 2$ index were used. Meta-analysis results were expressed graphically as forest plots. All statistical analyses were done by CMA version 2.2.

\section{Results}

\section{Results of the search}

Figure 1 shows the PRISMA flow diagram for study inclusion. The electronic search led to 192 publications. After excluding the irrelevant records based on the title and abstract review, 6 studies were reviewed by their full text, among which 3 were excluded due to duplication and 3 studies met our inclusion criteria. The RCTs were published between 2012 and 2014. Characteristics of included studies are presented in Table 1.

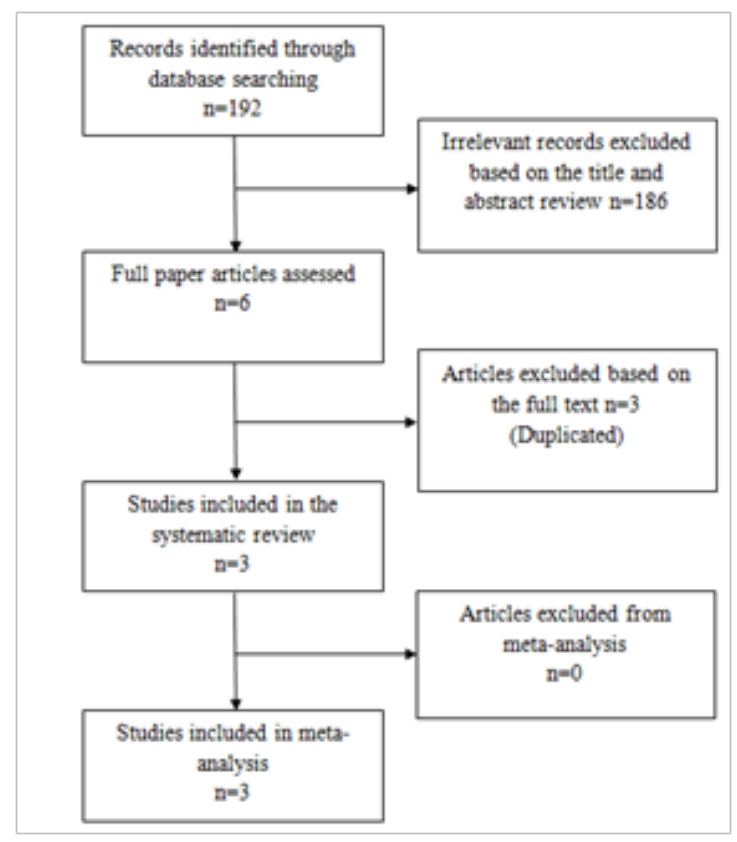

Figure I PRISMA Flow chart for the Results of the literature search. 
Table I Characteristics of each included study

\begin{tabular}{|c|c|c|c|c|}
\hline First author \& year & Country & Participants & $\begin{array}{l}\text { Interventions \& } \\
\text { comparisons }\end{array}$ & $\begin{array}{l}\text { Outcomes (labor pain } \\
\text { score) }\end{array}$ \\
\hline Kaviani, ${ }^{33}$ & Iran & $\begin{array}{l}\text { Primiparous participants with } \\
\text { singlefetus, gestational age }>36 \text { weeks } \\
\text { and cervical dilatation } 3-4 \mathrm{~cm} \text { were } \\
\text { included. } \\
\text { Women with medical or obstetrical } \\
\text { complications, asthma, allergy, common } \\
\text { cold, elective } \mathrm{C} / \mathrm{S} \text {, the use of other } \\
\text { sedative methods were excluded. }\end{array}$ & $\begin{array}{l}\text { Group I }(n=80) \text { : } \\
\text { received } 0.1 \mathrm{ml} \text { of lavender oil } \\
\text { mixed with I ml of distilled } \\
\text { water, via tissues attached } \\
\text { to their gown close to } \\
\text { theirnostrils } \\
\text { Group } 2(n=80) \text { : received just } \\
2 \text { cc of distilled water via the } \\
\text { same way. }\end{array}$ & $\begin{array}{l}\text { A significant decrease } \\
\text { in labor pain } 30 \text { and } 60 \\
\text { min after intervention in } \\
\text { Lavender group }\end{array}$ \\
\hline Mohamadkhani ${ }^{33}$ & Iran & $\begin{array}{l}\text { Nulliparous Iranian women with age } \\
\text { of } 18-35 \text { years, full term low risk } \\
\text { pregnancy at the beginning of active } \\
\text { phase of labor were included. } \\
\text { The athletic women or the cases of } \\
\text { addiction, using analgesic during } 3 \mathrm{~h} \\
\text { before and during the intervention, the } \\
\text { use of oxytocin, history of infertility, } \\
\text { eczema, allergy to essences oils were } \\
\text { excluded. }\end{array}$ & $\begin{array}{l}\text { Group I }(n=30) \text { : received } \\
\text { massage aromatherapy } \\
\text { with Lavender oil mixed in } \\
\text { Almond oil at dilatation of } \\
4-5 \mathrm{~cm}, 6-7 \mathrm{~cm} \text { and } 8-10 \mathrm{~cm} \text {, } \\
\text { for } 3 \times 20 \mathrm{~min} \\
\text { Group } 2(n=30) \text { : received } \\
\text { massage with Almond oil } \\
\text { Group } 3(n=30) \text { : received } \\
\text { only massage }\end{array}$ & $\begin{array}{l}\text { A significant decrease in } \\
\text { overall mean pain score } \\
\text { measured } 3 \text { times at } 4-5 \mathrm{~cm} \text {, } \\
6-7 \mathrm{~cm} \text { and } 8-10 \mathrm{~cm} \text { of } \\
\text { dilatation in each group } \\
\text { before and after intervention }\end{array}$ \\
\hline Vakilian $^{34}$ & Iran & $\begin{array}{l}\text { Multiparous women with single fetus, } \\
\text { no acute and chronic diseases, no } \\
\text { history of acute and chronic pain and } \\
\text { no history of allergies were included. } \\
\text { Women with systolic } \mathrm{BP}<95 \mathrm{mmHg} \text {, } \\
\text { lavender allergy or intolerance or } \\
\text { vaginal bleeding were excluded. }\end{array}$ & $\begin{array}{l}\text { Group I }(n=60) \text { : received } \\
\text { conducted cool vapor of } \\
\text { essential oil of lavender } \\
\text { Group } 2(n=5 I) \text { : received } \\
\text { cool water vapor }\end{array}$ & $\begin{array}{l}\text { A significant difference } \\
\text { between pain scores before } \\
\text { and after intervention with } \\
\text { Lavender aromatherapy }\end{array}$ \\
\hline
\end{tabular}

\section{Participants and settings}

Studies included in the systematic review ranged from $90^{32}$ to $160^{33}$ participants per study. Two studies recruited nulliparous women. Multiparous women were recruited in one study. ${ }^{34}$ In two of trials studies the intervention was performed at the beginning of active phase of labor. ${ }^{32,33}$ In another study it was not mentioned clearly. ${ }^{34}$ All of studies were conducted in Iran.

\section{Types of intervention}

In two of studies, Lavender aromatherapy was applied via inhalation method: conducted cool vapor of essential oil of lavender ${ }^{34}$ or Lavender oil mixed with water on the tissues attached to gown close to nostril. ${ }^{33}$ Mohamadkhani ${ }^{32}$ had used massage aromatherapy with Lavender oil mixed in Almond oil. ${ }^{32}$ In two trials studies, the duration of time assigned to the aromatherapy intervention was not mentioned. ${ }^{33,34}$ Mohamadkhani ${ }^{32}$ had explained that aromatherapy was applied for $3 \times 20$ min during and between contractions. ${ }^{32}$

\section{Types of control groups}

In trials related to inhalation Lavender aromatherapy, aromatherapy was compared with cool water vapor ${ }^{34}$ or tissues impregnated with a few drops of water. ${ }^{33}$ In massage aromatherapy control groups were massage with Almond oil or only massage. ${ }^{32}$

\section{Description of risk of bias}

Figure 2 as a methodological quality graph shows a summary of the risk of bias assessments for all of the included studies. The methodological quality summary for each included study has been summarized in Figure 3. Overall, no one of the included trials was at a low risk of bias on all of domains. The method of sequence generation was not mentioned in one of included studies. ${ }^{33}$ The methods used to conceal group allocation were also frequently not described in trials. ${ }^{32,33}$ Only Vakilian's studies reported adequate allocation concealment using numbered sealed opaque envelops. ${ }^{34}$ In most of trials the intervention could not be administered blind to participants or clinical careers. So, all of including studies had a high or unclear risk of performance bias. Vakilian's study had an unclear risk of detection bias; as the blinding of outcomes assessors to group allocation was not described. ${ }^{34}$ One study had a high risk of attrition bias which all of $\mathrm{C} / \mathrm{S}$ births were excluded from analysis of labor pain; also the proportions of missing data were unbalanced across the groups. ${ }^{34}$ The risk of reporting bias was at a low risk of bias in two of trials. ${ }^{33,34}$

\section{Outcome measures}

Figure 4 shows the forest plot of Lavender aromatherapy effect on the labor pain. The results showed that Lavender aromatherapy 
via inhalation decreased the labor pain by the order of $-0.476[-0.718$ $0.235], \mathrm{p}=0.000$. Cochrane $\mathrm{Q}$ value was $0.14, \mathrm{df}=1 \mathrm{p}=0.70$ and $\mathrm{I}^{2}=0 \%$. Also, massage aromatherapy by lavender oil decreased the labor pain significantly $(-0.907[-1.438--0.375], \mathrm{p}=0.001)$.

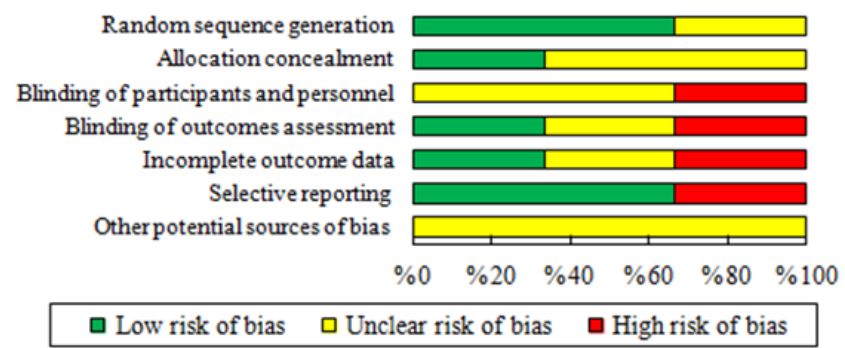

Figure 2 Risk of bias' graph: Systematic review authors' judgments about each risk of bias domains presented as percentages across all included studies.

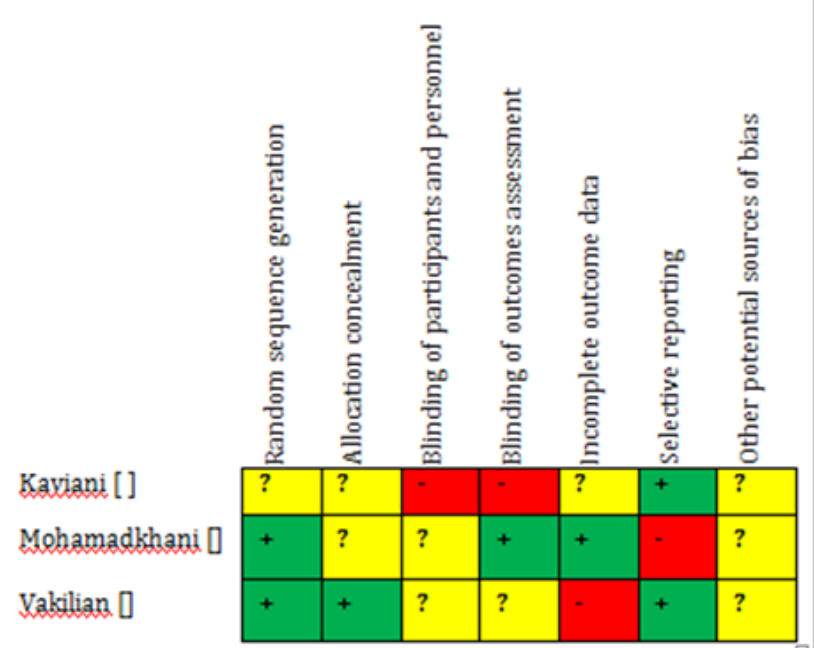

Figure 3 Risk of bias' summary: Systematic review authors' judgments about each risk of bias item for each included study.

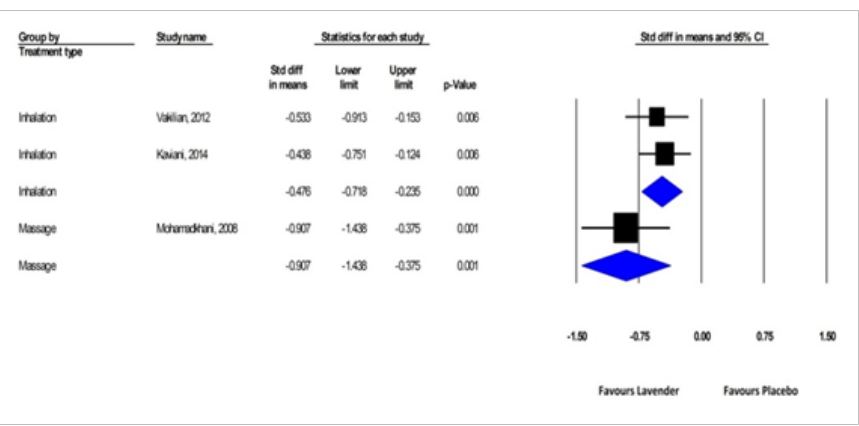

Figure 4 Forest plot of the meta-analysis.

\section{Discussion}

An overview of the results of clinical trials presented that Lavender aromatherapy in laboring women can reduce labor pain. The main mechanism of aromatherapy remains unknown. Some studies showed that aromatherapy with essential oils does not cause any change in blood pressure or heart rate and also improves physiological indices such as mental state, mood and anxiety level. ${ }^{35}$ There is a close relationship between anxiety and labor pain, followed by fear of childbirth may cause maternal anxiety during labor and stimulate the autonomous nervous system and expand hormonal secretion such as adrenaline and noradrenaline and cortisol. One of the mechanisms of action of Lavender aromatherapy is that Lavender oil in the role of an essential oil is absorbed through breathing and can reduce cortisol secretion or increase serotonin. Secretion As the findings of Mirzaei's study showed that Lavender aromatherapy reduced the level of maternal anxiety, cortisol secretion and increased serotonin secretion of the digestive tract during labor. ${ }^{36,37}$

The primary components of lavender oil are linalool (51\%) and linalyl acetate (35\%). Linalool inhibits the release of acetylcholine and makes changes in ion channel function at the neuromuscular junction. In addition, linalyl acetate has narcotic effects and linalool also acts as a sedative. This function shows the justification for the use of Lavenderoilin traditional herbal medicine. Since the massage facilitates the absorption of essential oils from the skin, so linalool and Lynalyl acetate will be absorbed within 5 minutes of skin massage and plasma concentration will be reached its maximum after about 20minutes. ${ }^{38-40}$ In addition, the decrease in labor pain that occurs with aromatherapy might be attributed to distraction from sense of pain. Distraction includes providing childbearing women with specific activities so that conscious thoughts and anxieties are reduced..$^{41}$ It seems that the smell of lavender or massage action, are along with a lack of focus on labor pain.

The authors of this meta-analysis, tried to minimize potential biases that threaten the validity of the study. For example, our search strategy was comprehensive. Two authors independently performed the search, extracted data, and assessed each study quality. Also, no time and language limits were considered in searching. There were several issues in the context of clinical trials included in this review which readers should bear them in mind when reading and interpreting the results. In general, the quality of clinical trials was moderate. Most of the studies presented few details about the exact method. In some of studies blinding of participants was impossible. Also a high level of attrition in one of the studies ${ }^{34}$ means that the primary balance was created by random assignment of subjects to intervention and control groups may be damaged. Another potential limitation was the small sample size of clinical trials.

\section{Conclusion}

Although the results of clinical trials showed a reduction in labor pain with Lavender aromatherapy via massage and inhalation, but the authors of the study believe that more accurate clinical trials with particular attention to blinding, attrition and selective reporting of outcomes are necessary to create evidence-based guidelines on the use of Lavender aromatherapy for parturient women in reducing labor pain.

\section{Acknowledgements}

None.

\section{Conflict of interest}

The author declares no conflict of interest.

\section{References}

I. Calik KY, Komurcu N. Effects of SP6 Acupuncture point stimulation on labor pain and duration of labor. Iranian Red Crescent Medical Journal. 2014;16(10):el646I. 
2. Rai R, Uprety D, Pradhan T, et al. Subcutaneous sterile water injection for labor pain: A randomized controlled trial. Nepal Journal of Obstetrics and Gynecology. 2014;8(2):68-70.

3. Dong C, Hu L, Liang F, et al. Effects of electro-acupuncture on labor pain management. Archives of gynecology and obstetrics. 20I4;29I(3):53I-536.

4. Gibbons L, Belizán JM, Lauer JA, et al. The global numbers and costs of additionally needed and unnecessary caesarean sections performed per year: overuse as a barrier to universal coverage. World health report. 20I0;30: $|-3|$.

5. Ahmad Nia S, Delavar B, Eini Zinab H, et al. Caesarean section in the islamic republic of iran: prevalence and some sociodemographic correlates. East Mediterr Health J. 2009; I 5(6): I 389-1398.

6. Hodnett ED. Pain and women's satisfaction with the experience of childbirth:a systematic review. American journal of obstetrics and gynecology. 2002; I86(5):SI60-72.

7. Lang A, Sorrell J, Rodgers C, Lebeck M.Anxiety sensitivity as a predictor of labor pain. European Journal of Pain. 2006; 10(3):263-270.

8. Cunningham F, Leveno K, Bloom S, et al. Williams Obstetrics. 23rd ed. New York, USA: McGraw-Hill; 2010.

9. Jones L. Pain management for women in labour:an overview of systematic reviews. Journal of Evidence-Based Medicine. 20I 2;5(2): I0I-102.

10. Forrester L, Maayan N, Orrell M, et al. Aromatherapy for promotion of relaxation and sleep, relief of pain, and reduction of depressive symptoms in dementia. Health. 2014.

I I. Valiani M, Shiran E, Kianpour M, et al. Reviewing the effect of reflexology on the pain and certain features and outcomes of the labor on the primiparous women. Iranian journal of nursing and midwifery research. 2010; I5(SuppII):302-310.

12. Makvandi S, Latifnejad Roudsari R, Sadeghi R, et al. Effect of birth ball on labor pain relief: A systematic review and meta-analysis. Journal of Obstetrics and Gynaecology Research. 20I5;4I(II):I679-I686.

13. Makvandi S, Zargar Shoshtari S, Montazeri S, et al. The effect of chewing sugar-free gum on the anxiety level of active phase of labor in nulliparous women. Razi Journal of Medical Sciences. 20I 3;20(I I2):9-I5.

14. Tang SK, Tse M. Aromatherapy: does it help to relieve pain, depression, anxiety, and stress in community-dwelling older persons. BioMed research international. 2014. 12. p.

I5. Buckle J. Clinical aromatherapy. Essential oils in practice: Elsevier Health Sciences; 2014.

16. Rivard R, Crespin D, Finch M, et al. Effectiveness of Therapeutic Massage in Conjunction with Aromatherapy for Pain and Anxiety Relief of Hospitalized Patients. The Journal of Alternative and Complementary Medicine. 20I4;20(5):AI25-AI 25.

17. Hodge NS, McCarthy MS, Pierce RM.A prospective randomized study of the effectiveness of aromatherapy for relief of postoperative nausea and vomiting. Journal of Peri Anesthesia Nursing. 2014;29(I):5-1 I.

I8. Huntley A, Hunt R. Some patients experience relief from postoperative nausea with aromatherapy. Focus on Alternative and Complementary Therapies. 2014; I9(2): I I4-II5.

19. Ovayolu Ö, Seviğ Ü, Ovayolu N, et al. The effect of aromatherapy and massage administered in different ways to women with breast cancer on their symptoms and quality of life. International journal of nursing practice. 2014;20(4):408-17.

20. Vakilian K, Atarha M, Bekhradi R, et al. Healing advantages of lavender essential oil during episiotomy recovery: a clinical trial. Complementary therapies in clinical practice. 201 I; I7(1):50-53.
2I. Lane B, Cannella K, Bowen C, et al. Examination of the effectiveness of peppermint aromatherapy on nausea in women post $\mathrm{C}$-section. Journal of Holistic Nursing. 2012;30(2):90-104.

22. Bakhtshirin F, Abedi S, YusefiZoj P, et al. The effect of aromatherapy massage with lavender oil on severity of primary dysmenorrhea in Arsanjan students. Iranian journal of nursing and midwifery research. 20I5;20(I):I56-I60.

23. Rafsanjani SML, Vazirinejad R, Ismailzadeh S,et al. Comparison of the efficacy of massage and aromatherapy massage with geranium on depression in postmenopausal women: a clinical trial. Zahedan Journal of Research in Medical Sciences. 20I5;I5:29-3I.

24. Tillett J,Ames D.The uses of aromatherapy in women's health. The Journal of perinatal \& neonatal nursing. 2010;24(3):238-45.

25. Burns E, Blamey C. Complementary medicine. Using aromatherapy in childbirth. Nursing times. 1993;90(9):54-60.

26. Joseph RM, Fernandes P.Effectiveness of jasmine oil massage on reduction of labor pain among primigravida mothers. Nitte University Journal of Health Science. 2013;3(4): 104-107.

27. Goldberg L. Massage and aromatherapy: a practical approach: Nelson Thornes. England: Springer; 200I,

28. Moeini M, Khadibi M, Bekhradi R, et al. Effect of aromatherapy on the quality of sleep in ischemic heart disease patients hospitalized in intensive care units of heart hospitals of the Isfahan University of Medical Sciences. Iran J Nurs Midwifery Res. 2010;15(4):234.

29. Tournaire M, Theau Yonneau A. Complementary and alternative approaches to pain relief during labor. Evid Based Complement Alternat Med. 2007;4(4):409-417.

30. Jaradat NA. Medical plants utilized in Palestinian folk medicine for treatment of diabetes mellitus and cardiac diseases. Journal of Al Aqsa Unv. 2005;9:1-28.

3I. Higgins JPT, Green S. Cochrane handbook for systematic reviews of interventions version 5.I.0. the cochrane collaboration; 20 I I.

32. Mohamadkhani Shahri L, Sabet Birjandi S, Mohamadkhani Shahri H. Effect of massage Aromatherapy with lavandula on the duration of first and second stage of labor in nulliparous women. Bimonthly Journal of Hormozgan University of Medical Sciences. 20I3; I7(2): I45-54.

33. Kaviani M,Azima S,Alavi N,Tabaei MH.The effect of lavender aromatherapy on pain perception and intrapartum outcome in primiparous women. British Journal of Midwifery. 20 |4;22(2): I 25-128.

34. Vakilian K, Karamat A, Mousavi A, et al. The effect of Lavender essence via inhalation method on labor pain. Journal of Shahrekord University of Medical Sciences. 20I2; I4(I):34-40.

35. Stevensen C. The psychophysiological effects of aromatherapy massage following cardiac surgery. Complementary Therapies in Medicine. 1994;2(I):27-35

36. Beesley A, Hardcastle J, Hardcastle P, et al. Influence of peppermint oil on absorptive and secretory processes in rat small intestine. Gut. 1996;39(2):214-219.

37. Mirzaei F, Keshtgar S, Kaviani M,The effect of lavender essence smelling during labor on cortisol and serotonin plasma levels and anxiety reduction in nulliparous women. Journal of Kerman University of Medical Sciences. 2009; I6(3):245-254.

38. de Moura Linck V, da Silva AL, et al. Inhaled linalool-induced sedation in mice. Phytomedicine. 2009; I6(4):303-307.

39. Re L, Barocci S, Sonnino S, et al. Linalool modifies the nicotinic receptor-ion channel kinetics at the mouse neuromuscular junction. Pharmacological Research. 2000;42(2): I77-182. 
40. Peana AT, D Aquila PS, Panin F, et al. Anti-inflammatory activity of linalool and linalyl acetate constituents of essential oils. Phytomedicine. 2002;9(8):72I-726.
4I. Adams ED, Bianchi AL. A practical approach to labor support. J Obstet Gynecol Neonatal Nurs. 2008;37(I): I06-II5. 